Derecho procesal civil 
lus et Praxis, Revista de la Facultad de Derecho

N. ${ }^{\circ} 43,2012$

ISSN 1027-8168

pp. $49-72$

\title{
La oralidad en el proceso contencioso-administrativo en el Perú
}

\author{
Elizabeth Mac Rae Thays
}

El proceso contencioso-administrativo en el Perú es el instrumento de control jurisdiccional externo de la actuación administrativa, instaurado para que el órgano judicial conozca los conflictos de intereses o incertidumbres jurídicas que surjan con la Administración Pública - los cuales se pueden generar por la acción u omisión de esta-, siempre que el administrado haya agotado la vía administrativa, salvo en los casos expresamente previstos por la propia norma, donde ello no se requiera. La jurisprudencia ha establecido que tampoco se requiere dicho agotamiento cuando se cuestione una actuación material que no se sustenta en acto administrativo.

El contencioso-administrativo también es el cauce procesal para aquellos supuestos excepcionales en que se faculta a la Administración Pública a solicitar al Poder Judicial la declaración de nulidad de sus propios actos declarativos de derechos a favor de un particular, cuando se ha vencido el plazo para declarar su nulidad de oficio en sede administrativa (proceso de lesividad).

El juzgador, aplicando la norma pertinente, debe resolver las pretensiones de quienes ejercen su derecho a la tutela jurisdiccional efectiva, teniendo la obligación de resolver, aun en el caso de vacío o deficiencia de la ley, aplicando los principios del derecho administrativo.

El proceso contencioso-administrativo tiene sustento de orden constitucional: la Constitución de 1993, en su artículo 148, dispone: "Las resoluciones administrativas que causan estado son susceptibles de 
impugnación mediante la acción contencioso-administrativa", norma que debe concordarse con el inciso 3) del artículo 139 del citado texto constitucional, que establece el derecho de todo ciudadano a la tutela judicial efectiva. El proceso contencioso-administrativo permite un freno y contrapeso entre los diversos poderes del Estado.

\section{Antecedentes legislativos del proceso contencioso-administrativo en el Perú}

Jorge Danós Ordóñez (s/f), al analizar la evolución del proceso contencioso-administrativo en el Perú, indica que, en el siglo XX, probablemente la primera norma legal que con carácter general estableció la posibilidad de cuestionar ante el Poder Judicial los actos de la Administración Pública fue el artículo 94 de la Ley Orgánica del Poder Judicial de 1912. ${ }^{1}$

La Constitución de 1933 incorporó para el control judicial de las normas reglamentarias a la "acción popular", que subsiste hasta nuestros días con carácter de proceso constitucional para el control jurisdiccional de las disposiciones de carácter general de rango subordinado a la ley. ${ }^{2}$

La Ley Orgánica del Poder Judicial, aprobada por Decreto Ley 14605, promulgada en el año 1963, también estableció la posibilidad de cuestionar ante el Poder Judicial las actuaciones administrativas, aunque sin configurar un proceso específico.

El proceso administrativo se institucionaliza en el Perú con la Constitución de 1979, que en su artículo 240 incorpora las "acciones contencioso-administrativas". ${ }^{3}$ Pero este proceso no es el único mecanismo

1 Ley Orgánica del Poder Judicial del año 1912

Artículo 94.- Corresponde a los jueces de primera instancia de Lima, conocer, en primera instancia, de los despojos que infiera el Gobierno y de las demandas que contra él se interpongan sobre derechos que hubiese violado o desconocido ejerciendo funciones administrativas.

$2 \mathrm{Al}$ respecto, Danós (s/f) precisa que esto denota una importante diferencia con la mayor parte de países con un régimen administrativo semejante al nuestro, en los que el control judicial de la legalidad de los reglamentos es generalmente materia de los procesos contencioso-administrativos.

3 A pesar de que la Constitución de 1979 estableció como mecanismo idóneo, para el control de la Administración, a la acción contencioso-administrativa, esta careció, hasta el Código Procesal Civil promulgado en 1993, de una norma procesal que regulara específicamente su trámite, a diferencia de los procesos constitucionales. 
para el control jurisdiccional de la Administración; también están procesos constitucionales como la acción de amparo, ${ }^{4}$ proceso destinado a la tutela de los derechos fundamentales cuando "sean vulnerados o amenazados por cualquier autoridad, funcionario o persona". Este proceso constitucional se ofrecía como alternativo al proceso contenciosoadministrativo, para el control de la actuación de los poderes públicos. También se mantuvo a la acción popular, para el control judicial de la legalidad y constitucionalidad de los reglamentos y de toda otra norma de carácter general con rango inferior a la ley.

Debido a la falta de una ley que regulara la acción contenciosoadministrativa, el Poder Ejecutivo reglamentó el proceso contenciosoadministrativo laboral mediante el Decreto Supremo 037-90-TR, publicado el 13 de junio de 1990, referido a "las acciones contencioso-administrativas que se interpongan contra resoluciones de la Administración que causen estado en materia laboral", procesos que se tramitarían ante los tribunales especializados, en materia laboral, de Lima.

Es en 1991, con la Ley Orgánica del Poder Judicial, que se establecen reglas procesales específicas para los denominados procesos contencioso-administrativos - en un capítulo ubicado en las disposiciones finales de dicha ley-, las que fueron derogadas mediante el Decreto Legislativo 767, que aprobó el nuevo Código Procesal Civil en 1993. Esta norma procesal recogía los preceptos del Código Procesal Iberoamericano, introduciendo la oralidad en el proceso contencioso-administrativo.

El Código Procesal Civil de 1993 reguló el proceso contenciosoadministrativo como "impugnación de acto o resolución administrativa" - proceso de competencia del juez civil-, una modalidad de los denominados procesos abreviados, ${ }^{5}$ limitando la acción del juzgador a declarar la nulidad o invalidez de los actos administrativos.

4 El amparo y el hábeas corpus fueron regulados por la Ley 23506, desde 1982, y la acción popular fue desarrollada mediante la Ley 24968, desde finales de 1988.

5 Danós (s/f) indica que, no obstante, existían normas especiales para la impugnación de resoluciones administrativas, como la Ley Procesal del Trabajo, que reproducía las normas del Código Procesal Civil con el objeto de regular las controversias que se pudieran suscitar ante las Salas Especializadas en lo Laboral, respecto de las actuaciones de las autoridades administrativas competentes en materia laboral. También el Código Tributario regulaba el proceso contenciosoadministrativo para impugnar ante el Poder Judicial resoluciones de las entidades que cumplieran funciones de administración tributaria. 
La Constitución de 1993 también comprende como mecanismos de control jurisdiccional de la Administración al proceso contenciosoadministrativo; al proceso constitucional de amparo, para la protección de los derechos constitucionales distintos de la libertad individual; al proceso constitucional de acción popular, para el control judicial de la legalidad de las disposiciones reglamentarias; y crea dos nuevos procesos constitucionales destinados en gran parte al control jurídico de la Administración Pública: el proceso de hábeas data, mediante el cual los ciudadanos pueden impugnar ante el juez la negativa de la Administración Pública a sus solicitudes de acceso a la información que obra en su poder, o pueden solicitar la protección de sus datos personales respecto de los servicios informáticos, públicos o privados; y el proceso de acción de cumplimiento, mediante el cual se puede acudir al juez para solicitarle que requiera a cualquier autoridad o funcionario de la Administración Pública renuente a acatar una norma legal o un acto administrativo, que cumpla con sus obligaciones.

En abril del 2001 se promulga la Ley de Procedimiento Administrativo General - Ley 27444-, y en diciembre del mismo año, la Ley que regula el Proceso Contencioso-Administrativo (LPCA) - Ley 275846-, proceso distinto del proceso civil. Esta última legisla las instituciones básicas y es, en esencia, una norma de remisión al Código Procesal Civil en aquello que no ha sido regulado en forma expresa.

En el 2004 entra en vigencia el Código Procesal Constitucional - Ley 28237-, que modifica el esquema vigente para los procesos constitucionales, pasando de un esquema alternativo a un proceso residual, lo que motiva un incremento notable en los procesos contencioso-administrativos.

Con la Ley 28531, publicada el 26 de mayo del 2005, se modifica el proceso contencioso-administrativo. Posteriormente, la LPCA sufre una modificación en el 2008, con el Decreto Legislativo 1067 - publicado el 28 de junio del 2008-; otra en mayo del 2009, a través de la Ley 29364; ${ }^{7}$

6 Publicada en el diario oficial El Peruano el 7 de diciembre del 2001. Entró en vigencia el 2002.

7 Ley 29364

Primera disposición modificatoria.- Modificación del Texto Único Ordenado de la Ley 27584, Ley que Regula el Proceso Contencioso Administrativo.

Modifícase el artículo 11 del Texto Único Ordenado de la Ley 27584, Ley que 
y otra en el 2011, mediante la Ley $29782^{8}$ - publicada el 28 de julio del $2011-$, con lo que se regresa a un sistema similar al que existía antes de ser modificado el proceso contencioso-administrativo.

El legislador ha optado por el sistema judicial de control jurisdiccional de la actuación de la Administración Pública; por tanto, no se ha considerado justificado crear una organización diferente de la jurisdicción ordinaria, similar al Consejo de Estado de Francia, sistema que ha sido adoptado por otros países, como Colombia. Si bien en el Perú existen experiencias sobre un control paralelo al Poder Judicial, pues duran-

Regula el Proceso Contencioso Administrativo, aprobado por Decreto Supremo 013-2008-JUS, conforme al texto siguiente:

"Artículo 11.- Competencia funcional

Son competentes para conocer el proceso contencioso administrativo el juez especializado y la Sala Especializada en lo Contencioso Administrativo, en primer y segundo grado, respectivamente.

En los lugares donde no exista juez o Sala Especializada en lo Contencioso Administrativo, es competente el juez en lo civil o el juez mixto, en su caso, o la Sala Civil correspondiente".

8 Ley 29782

Disposiciones complementarias modificatorias

Tercera.- Modificación del Texto Único Ordenado de la Ley 27584, Ley que Regula el Proceso Contencioso Administrativo, aprobado por el Decreto Supremo 013-2008-JUS.

Modifícase el segundo párrafo e incorporase un tercer párrafo al artículo 11 del Texto Único Ordenado de la Ley 27584, Ley que Regula el Proceso Contencioso Administrativo, aprobado por el Decreto Supremo 013-2008-JUS, conforme al texto siguiente:

"Artículo 11. Competencia funcional

$[\ldots]$.

Cuando el objeto de la demanda verse sobre actuaciones del Banco Central de Reserva del Perú (BCR), Superintendencia del Mercado de Valores (SMV), y de la Superintendencia de Banca, Seguros y Administradoras Privadas de Fondos de Pensiones (SBS), es competente, en primera instancia, la Sala Especializada en lo Contencioso Administrativo de la Corte Superior respectiva. En este caso, la Sala Civil de la Corte Suprema resuelve en apelación y la Sala Constitucional y Social en casación, si fuera el caso. Es competente para conocer la solicitud de medida cautelar la Sala Especializada en lo Contencioso Administrativo de la Corte Superior.

En los lugares donde no exista juez o Sala Especializada en lo Contencioso Administrativo, es competente el juez en lo civil o el juez mixto, en su caso, o la Sala Civil correspondiente". 
te el gobierno militar que gobernó entre 1968 y 1980 se crearon organizaciones paralelas a la judicial ordinaria, denominadas "fueros privativos", en los ámbitos laboral y agrario - compuestos por jueces de primera instancia y salas de apelación, nivel superior con competencia para decidir con carácter de cosa juzgada - , por mandato de la Constitución de 1979 estos "fueros privativos" fueron integrados al Poder Judicial en la jurisdicción ordinaria.

El proceso contencioso-administrativo unifica la anterior regulación existente en la materia, si bien la dispersión legislativa propia del ámbito administrativo aún se mantiene y se da en diversos cuerpos legales, como el Código Tributario, la Ley Procesal del Trabajo, normas de derecho del consumidor, derecho de autor y concursales - que se aplican en los tribunales de Indecopi-, normas de derecho bancario y del sistema financiero y de seguros - que se aplican por la Superintendencia de Banca y Seguros-, etc.

Muchas de estas normas también regulaban aspectos del ámbito contencioso, rompiendo la homogeneidad que debería existir en el tratamiento legislativo de la materia mediante el establecimiento de reglas comunes en cuestión de plazos de interposición de la demanda, trámite del proceso, ejecución de sentencias, etc. Esto quedó proscrito con la entrada en vigencia de la norma procesal, esto es, la LPCA.

\section{El proceso contencioso-administrativo vigente en el Perú}

El proceso contencioso-administrativo recogido en la Constitución Política de 1993 no permite la existencia de ámbitos de la actividad administrativa que puedan considerarse exentos o inmunes a un eventual control jurisdiccional por quienes se consideran afectados. Se garantiza el derecho de los particulares a poder cuestionar ante el Poder Judicial las decisiones administrativas que los afecten, a fin de verificarse la legitimidad de la actuación de todas las entidades administrativas.

Mediante el proceso contencioso se garantiza una de las premisas básicas del Estado de derecho, que es la subordinación de toda la actividad administrativa al principio de legalidad. En tal virtud, los afectados por una actuación administrativa están facultados para demandar ante el Poder Judicial la satisfacción jurídica de sus pretensiones contra la Administración Pública. 
La ley regula los aspectos que diferencian al proceso contenciosoadministrativo del proceso civil, en materias como principios, actuaciones administrativas impugnables, pretensiones, instancias competentes, sujetos, cuestiones procedimentales, medidas cautelares (los requisitos de admisibilidad y procedencia), régimen de las pruebas, así como efectos y ejecución de las sentencias. En los demás aspectos, por tratarse de materias predominantemente del ámbito del derecho procesal, la norma remite su regulación al Código Procesal Civil.

\subsection{Principios del proceso contencioso-administrativo}

Son cuatro los principios que rigen el proceso contencioso-administrativo, el cual comparte todos los principios que inspiran a todos los procesos contenidos en la Constitución y la Ley Orgánica del Poder Judicial. No obstante ello, conforme señala Priori Posada (2006: 90), debe tenerse en cuenta que "la naturaleza de los conflictos que son materia del proceso contencioso-administrativo es sustancialmente distinta a la naturaleza de los conflictos que son materia de un proceso civil", y que para comprender dicha diferencia han sido elaboradas fundamentalmente dos teorías, complementarias entre sí: a) la teoría de la sujeción o subordinación, y b) la teoría del sujeto. ${ }^{9}$

Los principios previstos en el artículo 2 del Texto Único Ordenado (TUO) de la LPCA son aquellos que le otorgan al proceso contenciosoadministrativo su identidad propia. Ellos son:

a) El principio de integración, conforme al cual los jueces no pueden dejar de administrar justicia ante vacío o deficiencia de la ley. Si

9 Priori Posada (2006: 91).

La teoría de la sujeción o subordinación. Respecto a esta teoría, en los conflictos de derecho administrativo existe una desigualdad natural, pues uno de los sujetos del conflicto es el Estado, quien actúa en ejercicio de una función estatal, como es la administrativa, lo que determina una relación de subordinación entre los sujetos de conflicto.

La teoría del sujeto. Conforme a esta teoría, dentro de un conflicto de naturaleza administrativa, la actividad de uno de los sujetos del conflicto se sujeta a una norma que no obliga o faculta a cualquier persona, sino necesariamente a un sujeto, que es portador de la autoridad soberana. Los conflictos de naturaleza civil, en cambio, surgen en virtud de actividades que pueden ser realizadas por cualquiera. Siendo que la naturaleza de los conflictos civiles y administrativos es sustancialmente distinta, las reglas y principios que rigen los proceso civiles y administrativos también son sustancialmente distintos. 
durante la tramitación de los procesos contencioso-administrativos se determina la existencia de defecto o deficiencia de la ley sustantiva aplicable al caso que es objeto del proceso, los jueces deberán integrar los vacíos o lagunas utilizando los principios propios del derecho administrativo. La Ley 27444, del Procedimiento Administrativo General, contiene una extensa relación de principios del procedimiento administrativo en el artículo IV de su título preliminar.

Si bien el principio de integración también está comprendido entre los principios previstos en el Código Procesal Civil - artículo III de su título preliminar-, el legislador ha considerado necesario que se puntualice en la norma contencioso-administrativa, como norma especial, que ante la deficiencia por vacío o laguna son aplicables los principios del derecho administrativo.

b) El principio de igualdad procesal, conforme al cual las partes, durante la tramitación del proceso, deberán ser tratadas con igualdad. Lo que se pretende es crear un instrumento de equiparación, precisamente ante la evidencia de un trato diferenciado y favorable al Estado. La norma busca otorgar simetría en cuanto al trato que se debe dar a las partes, para garantizar una efectiva tutela de las situaciones jurídicas de los administrados. Al respecto, Priori Posada (2006: 112) menciona: “La reforma establecida por la ley apuesta por una equiparación de las partes en el proceso, pues resultaba a todas luces absurdo que el particular que se encuentra en una situación de subordinación frente a la Administración, tenga que seguir aceptando dicha subordinación dentro del proceso judicial".

c) El principio de favorecimiento del proceso, conforme al cual, si los jueces encargados de tramitar el proceso tienen una duda razonable acerca de la procedencia de la demanda, deberán preferir darle trámite, sin perjuicio de poder verificar el cumplimiento o incumplimiento de los requisitos de procedibilidad a lo largo del proceso. Se trata de un principio vinculado al principio conocido como pro actione. El objetivo es facilitar el acceso a los ciudadanos a la tutela judicial efectiva, a fin de evitar que interpretaciones en exceso formalistas menoscaben su derecho constitucional a cuestionar judicialmente actuaciones administrativas que consideren ilegales o arbitrarias. 
d) El principio de suplencia de oficio, por el cual los jueces del contencioso-administrativo deben suplir las deficiencias formales de las partes, así como disponer su subsanación en un plazo razonable. Este principio tiene dos fundamentos, uno de orden constitucional -el derecho a la tutela jurisdiccional efectiva-, y otro que radica en el rol del juez como director del proceso, de quien se pretende un rol proactivo para que procure que el proceso no se entorpezca con una deficiencia no sustancial, de tipo formal.

\subsection{Principios jurisprudenciales en materia contencioso-administrativa}

La LPCA contiene indudables avances al establecer cauces para que la jurisprudencia judicial genere criterios y doctrina que consoliden las instituciones propias del derecho administrativo, para lo cual establece la posibilidad de que se emitan principios jurisprudenciales que constituyan precedentes vinculantes, creándose así las bases para una especialización en la materia, que debería determinar la futura exigencia de jueces y salas especializadas en lo contencioso-administrativo, requisito esencial para otorgar la seguridad jurídica que permita la previsibilidad de los fallos jurisdiccionales.

\subsection{Sobre la especialización de los órganos jurisdiccionales}

La Ley consagra la creación de juzgados de primera instancia y de salas especializadas en las cortes superiores de justicia, para buscar garantizar mayor efectividad en las técnicas de control jurisdiccional de la Administración Pública. Se establece que el proceso deberá iniciarse en todos los casos ante el juez especializado en la materia, cuyas resoluciones pueden apelarse ante la respectiva sala especializada de la Corte Superior.

La Corte Suprema debería cumplir un rol exclusivamente casatorio con la modificación introducida en la Ley 29782 - publicada el 28 julio del 2011-, según la cual, cuando el objeto de la demanda verse sobre actuaciones del Banco Central de Reserva del Perú (BCR), la Superintendencia del Mercado de Valores (SMV) y la Superintendencia de Banca, Seguros y Administradoras Privadas de Fondos de Pensiones (SBS), es competente en primera instancia la sala especializada en lo contenciosoadministrativo de la corte superior respectiva, con lo que se regresa al esquema que fuera modificado y se deja de lado aquel en el cual la sala 
civil de la Corte Suprema conocía en segunda instancia y lo resuelto por esta era materia de recurso de casación por la sala constitucional y social - sin advertirse que ambas salas supremas tienen la misma jerarquía-, lo que distorsionaba la función de la Corte Suprema y le generaba una mayor carga procesal.

Se ha modificado la norma también con relación al modelo original, que buscaba una especialización contencioso-administrativa en general. Actualmente, con la Ley 29364, cuya segunda disposición modificatoria cambia el artículo 51 de la Ley Orgánica del Poder Judicial, los juzgados especializados de trabajo son competentes para conocer las demandas contencioso-administrativas en materia laboral y de seguridad social.

Es evidente que debe tenderse a una especialización en lo contencioso-administrativo; lo ideal es generar órganos subespecializados según las materias objeto de revisión. La especialización, hoy, se da en la Corte Superior de Justicia de Lima y en la Corte Superior de Justicia del Cusco, en las que existen jueces especializados en lo contencioso-administrativo, y se espera que paulatinamente esto se vaya extendiendo.

\subsection{Objeto del proceso contencioso-administrativo}

El TUO de la LPCA distingue entre actuaciones impugnables y pretensiones. Así, el artículo 4 dispone el control jurisdiccional de toda actuación administrativa en ejercicio de potestades reguladas por el derecho administrativo, y establece una relación de actuaciones impugnables:

a) Los actos administrativos y cualquier otra declaración administrativa, esto es, las declaraciones que realizan los órganos de la Administración en ejercicio de una potestad sujeta al derecho administrativo.

b) El silencio, la inercia o cualquier otra omisión formal de la Administración Pública.

c) La simple actuación material de la Administración sin cobertura formal; las actividades de ejecución de actos administrativos que transgredan el marco legal; las actuaciones sobre el personal dependiente de la Administración Pública.

Las pretensiones son los pedidos que el demandante dirige al juzgador a fin de que se pronuncie sobre la afectación que la Administración le ha causado por acción u omisión. Entre las pretensiones que los demandantes pueden formular en el proceso, se encuentran: 
a) La declaración de nulidad, total o parcial, o ineficacia del acto administrativo cuestionado.

b) El reconocimiento o restablecimiento del derecho o interés jurídicamente tutelado y la adopción de las medidas o actos necesarios para tales fines.

c) La declaración de contraria a derecho y el cese de toda actuación material que no se sustente en un acto administrativo.

d) Se ordene a la Administración Pública la realización de una determinada actuación a la que se encuentre obligada por mandato de la ley o en virtud de acto administrativo.

El proceso contencioso-administrativo se configura como un proceso de "plena jurisdicción" o "de carácter subjetivo". Los jueces no están restringidos a constatar la invalidez o nulidad del acto administrativo o su posible ineficacia - es decir, la mera carencia de efectos legales-, sino que deben entrar al fondo del asunto; esto se desprende de la redacción del artículo 41 del TUO de la LPCA, referido a las sentencias estimatorias o fundadas, norma que permite: el restablecimiento o reconocimiento de una situación jurídica individualizada, la cesación de la actuación material que no se sustente en acto administrativo y la adopción de cuanta medida sea necesaria para obtener la efectividad de la sentencia, así como la adopción de cuantas medidas sean necesarias para el restablecimiento o reconocimiento de la situación jurídica lesionada.

Mediante el contencioso-administrativo se controla la actuación de la Administración Pública en ejercicio de potestades reguladas por el derecho administrativo, de modo que el juez asume un rol de protección y satisfacción de los derechos e intereses de los particulares afectados por actuaciones administrativas. Pero la resolución de las controversias vinculadas a los procedimientos de suscripción y ejecución de los contratos celebrados por la Administración para la adquisición de suministros, la construcción de obras públicas o de otorgamiento de concesiones sobre servicios o infraestructura de dominio público no se resuelven mediante el proceso contencioso-administrativo, pues el marco legal de los contratos con el Estado dispone que los entes administrativos deben pactar con sus contratistas o concesionarios la realización de procesos arbitrales a fin de resolver las controversias derivadas de la relación contractual. Asimismo, el Decreto Legislativo 1017, Ley de Contrataciones del Estado, en su artículo 52 establece que los conflictos se resolverán mediante conciliación o arbitraje, dependiendo del monto de la 
contratación, manteniéndose lo previsto en la Ley 26850, de contrataciones y adquisiciones del Estado, ya derogada. La decisión obedece a la falta de celeridad de los órganos de justicia y a la falta de especialización de los magistrados. Además, en consonancia con diversos tratados internacionales multilaterales para la protección de inversiones, las controversias de mayor magnitud deberán ser resueltas por un tribunal arbitral con sede en el extranjero y constituido conforme a las reglas de un determinado centro de arbitraje internacional.

En el Perú, cerca de catorce tribunales administrativos resuelven controversias administrativas de los distintos sectores, desde el ámbito del Tribunal Fiscal (tributario y aduanero), el Tribunal Registral (registral), el Consejo de Minería (minero), los tribunales del Indecopi, el Tribunal del Servir (ámbito laboral público), el Osiptel, Osinergmin y Sunass (controversias entre empresas concesionarias y usuarios de servicios públicos), el SBS (controversias entre bancos y compañía de seguros y sus clientes), etc. Estos tribunales forman parte de la Administración Pública, son creados por una ley que les otorga competencia para resolver controversias, la mayor parte de las veces entre la Administración y los particulares - pero también de estos entre sí-, en última instancia administrativa, y están conformados por un cuerpo colegiado de funcionarios especializados.

\subsection{Rol del Ministerio Público en los procesos contencioso-administrativos}

De modo general, el papel que le asigna el ordenamiento jurídico al Ministerio Público (artículo $16^{10}$ del TUO de la LPCA) es el de dictaminador en los procesos especiales - aunque no en el proceso urgente (en primera instancia) - , antes de la emisión de la sentencia.

10 Texto Único Ordenado de la Ley 27584, aprobado por el Decreto Supremo 0132008-JUS.

Artículo 16.- Intervención del Ministerio Público

En el proceso contencioso administrativo el Ministerio Público interviene de la siguiente manera:

1. Como dictaminador, antes de la expedición de la resolución final y en casación. En este caso, vencido el plazo de 15 días para emitir dictamen, devolverá el expediente con o sin él, bajo responsabilidad funcional. [...]. 
También asume la calidad de parte demandante en la tutela de intereses difusos, aun cuando no existen a la fecha procesos en los cuales se haya podido desarrollar esta figura.

Entre las modificaciones efectuadas al texto original de la LPCA, se ha dispuesto establecer un término - bajo responsabilidad - dentro del cual el Ministerio Público deberá dictaminar o devolver el expediente, en aras de la celeridad procesal.

\subsection{Representación del Estado}

Como regla general, el artículo 17 del TUO de la LPCA señala que la representación y defensa judicial de las entidades administrativas estará a cargo de la respectiva procuraduría, regida por el Decreto Legislativo 1068, regulatorio del Sistema de Defensa Jurídica del Estado.

\subsection{Vías procedimentales}

Cuando el proceso contencioso-administrativo se regulaba por el Código Procesal Civil, se tramitaba como un proceso abreviado. Con la promulgación de la LPCA, se establecieron dos procesos: uno especial y otro sumario (este último, solo para ciertos supuestos). Una de las innovaciones del proceso especial en relación con el proceso anterior es que se elimina la primera audiencia, en la que se efectuaba el saneamiento procesal, se fijaban los puntos controvertidos y se admitían los medios probatorios, manteniéndose la audiencia de pruebas solo cuando deban actuarse dichos medios, aunque se deja en potestad del juzgador prescindir de ella, decisión que es (era) inimpugnable. Esta modificación legislativa se produjo por el colapso del sistema contencioso-administrativo, debido a la sobrecarga procesal y el reducido número de órganos jurisdiccionales especializados en la materia, viéndose este mecanismo como una alternativa para agilizar el trámite y reducir la duración de los procesos.

En el 2008, la LPCA fue modificada por el Decreto Legislativo 1067 - publicado el 28 de junio de ese año-. Las modificaciones se introdujeron en varios aspectos, uno de ellos el relacionado con la inimpugnabilidad de la decisión de prescindir de la audiencia de pruebas: ahora, esta decisión sí puede ser impugnada vía apelación, la cual se concede sin efecto suspensivo y con la calidad de diferida; es decir, el superior jerárquico resolverá la impugnación cuando conozca la apelación de la 
sentencia de primera instancia. Asimismo, el Decreto Legislativo 1067 derogó la norma relacionada con el proceso sumario e introdujo el proceso urgente en su reemplazo, con un trámite mucho más breve.

El TUO de la LPCA establece una tutela diferenciada que obedece a la naturaleza de las pretensiones demandadas. Regula dos procesos: el proceso urgente, para el cual establece un trámite de cognición sumaria y concentración procedimental, en donde las pretensiones que se pueden tramitar por esta vía solo serán las previstas por la norma; y el proceso especial, para todos los otros casos, con carácter lato y que será el proceso contencioso-administrativo por excelencia.

a) Proceso urgente. Diseñado básicamente para la protección de derechos fundamentales como el derecho pensionario y el derecho al trabajo, tiene un trámite procesal sumario y es netamente escrito.

Se tramitan como proceso urgente sólo las siguientes pretensiones:

1. El cese de cualquier actuación material que no se sustente en acto administrativo.

2. El cumplimiento, por la Administración, de una determinada actuación a la que se encuentre obligada por mandato de la ley o en virtud de acto administrativo firme.

3. Las relativas a materia provisional, en cuanto se refieran al contenido esencial del derecho a la pensión. El Tribunal Constitucional (TC), en la sentencia 1417-2005-PA/TC, estableció un precedente vinculante relacionado con el derecho pensionario, definiendo en el fundamento 37 de dicha sentencia todo aquello que forma parte del contenido esencial del derecho a la pensión: i) las disposiciones legales que establecen los requisitos del libre acceso al sistema de seguridad social consustanciales a la actividad laboral pública o privada, dependiente o independiente, y que permite dar inicio al periodo de aportaciones al Sistema Nacional de Pensiones; ii) las disposiciones legales que establecen los requisitos para la obtención de un derecho a la pensión; iii) aquellas pretensiones mediante las cuales se busque preservar el derecho concreto a un "mínimo vital"; iv) aun cuando, prima facie, las pensiones de viudez, orfandad y ascendientes no forman parte del contenido esencial del derecho fundamental a la pensión, en la medida en que el acceso a las prestaciones pensionarias sí lo es, son suscepti- 
bles de protección mediante amparo los supuestos en los que se deniegue el otorgamiento de una pensión de sobrevivencia, a pesar de cumplir con los requisitos legales para obtenerla; v) las afectaciones al derecho a la igualdad como consecuencia del distinto tratamiento (en la ley o en la aplicación de la ley) que dicho sistema dispense a personas que se encuentran en situación idéntica o sustancialmente análoga.

Para conceder la tutela urgente se requiere que del mérito de la demanda y de sus recaudos se advierta que, concurrentemente, existe:

a) Interés tutelable cierto y manifiesto;

b) Necesidad impostergable de tutela; $y$

c) Ausencia de otra vía que sea eficaz para la tutela del derecho invocado.

Las demandas cuyas pretensiones no satisfagan los requisitos para la tutela urgente se tramitarán conforme a las reglas que norman el proceso especial. Admitida la demanda como proceso urgente, se notifica a la otra parte para que en un plazo de tres días conteste. Vencido este plazo, con o sin absolución de la demanda, el juez dictará en la sentencia la medida que corresponda a la pretensión invocada dentro del plazo de cinco días. El plazo para apelar la sentencia es de cinco días, contados a partir de su notificación y se concede con efecto suspensivo.

Como se puede advertir de estas normas, el proceso es escrito y no se establece estación probatoria, de lo que se deduce que solo se admiten como medios probatorios documentos y no se considera a la oralidad en primera instancia. No se regula el trámite en segunda instancia, por lo que se aplican de manera supletoria las normas del proceso especial, con la única diferencia de que el expediente no se remite para dictamen al Ministerio Público. La oralidad se presenta solo si las partes solicitan informe oral ante la sala superior.

Con la finalidad de evitar dilaciones, en el proceso urgente, cuando las sentencias de primera y segunda instancia amparen la demanda, no procederá el recurso de casación.

b) Proceso especial. Es el proceso contencioso-administrativo por excelencia, con el cual se pueden tramitar todas las pretensiones 
no previstas para el proceso urgente. El trámite es bastante sencillo, pues, admitida la demanda, se notifica al demandado, quien tiene un plazo de diez días para contestarla.

El juez, si el demandado no contesta en el plazo, declarará su rebeldía. De contestar, el juez calificará la contestación, luego de lo cual, de haber interpuesto el demandado dentro de los cinco días excepciones o defensas previas, expedirá resolución pronunciándose sobre las excepciones, declarando la existencia de una relación jurídica procesal válida; o la nulidad y la consiguiente conclusión del proceso por invalidez insubsanable de la relación, precisando sus defectos; o, si fuere el caso, la concesión de un plazo, si los defectos de la relación fuesen subsanables.

Si el proceso se declara saneado, el auto de saneamiento deberá además contener la fijación de puntos controvertidos y la declaración de admisión o rechazo, según sea el caso, de los medios probatorios ofrecidos.

Solo cuando la actuación de los medios probatorios ofrecidos lo requiera, el juez señalará día y hora para la realización de una audiencia de pruebas. La decisión por la que se ordena la realización de esta audiencia o se prescinde de ella es impugnable y la apelación será concedida sin efecto suspensivo y con la calidad de diferida.

Luego de expedido el auto de saneamiento o de realizada la audiencia de pruebas, según sea el caso, el expediente será remitido al fiscal a fin de que emita dictamen. Con o sin este dictamen, el expediente será devuelto al Juzgado, el que se encargará de notificar la devolución del expediente y, en su caso, el dictamen fiscal a las partes.

Antes de dictar sentencia, las partes podrán solicitar al juez la realización de informe oral, el que será concedido por el solo mérito de la solicitud oportuna.

Como se puede advertir, solo en dos momentos en primera instancia se establece la oralidad: uno, cuando la actuación de los medios probatorios ofrecidos lo requiera, realizándose para ello una audiencia de pruebas; y dos, antes de dictarse sentencia, cuando las partes soliciten al juez la realización de informe oral. 


\subsection{Pruebas en el proceso especial}

El artículo 30 del TUO de la LPCA, de manera contraria a las modernas tendencias doctrinales en procesal y constitucional, restringe la actividad probatoria en el contencioso-administrativo, limitándola a las actuaciones recogidas en el procedimiento administrativo, salvo que se produzcan nuevos hechos (hechos nuevos propios) o que se trate de hechos que hayan sido conocidos con posterioridad al inicio del proceso (hechos nuevos impropios). En cualquiera de estos supuestos, podrán acompañarse los respectivos medios probatorios.

Por otro lado, de acumularse la pretensión indemnizatoria, podrán alegarse todos los hechos que le sirvan de sustento y ofrecerse los medios probatorios pertinentes.

Cuando se analizan en conjunto los demás dispositivos que regulan el régimen de los medios probatorios en el TUO de la LPCA (artículos 31 a 34), se advierte que no responden a la óptica restrictiva, pues fueron reproducidos del proyecto original que proclamaba el carácter amplio y abierto de la actividad probatoria en el proceso contencioso-administrativo.

Pese a las modificaciones legislativas, se continuó con la tendencia de considerar el proceso contencioso-administrativo como proceso que revisa el procedimiento seguido en vía administrativa; una continuación de lo actuado en lo administrativo. No obstante, el juzgador puede ordenar pruebas de oficio, pues la norma le da la facultad de poder, con ellas, cambiar la perspectiva de lo actuado en el procedimiento administrativo.

El artículo 24 del TUO de la LPCA prescribe que, al admitir a trámite la demanda, los jueces deberán ordenar a la entidad demandada la remisión del expediente relacionado o en el que se originó la actuación administrativa impugnada. Si se incumple tal orden, los jueces pueden optar por cualquiera de las siguientes medidas, sin que se suspenda la tramitación del proceso contencioso-administrativo: 1) prescindir del expediente administrativo, en cuyo caso el juez contencioso-administrativo, al momento de resolver, tendrá en cuenta la conducta procesal de la demandada; 2) reiterar el pedido, bajo apercibimiento de poner los hechos en conocimiento del Ministerio Público a fin de que inicie el proceso penal correspondiente.

Por otro lado, en los procesos de lesividad, esto es, aquellos en los que la entidad solicita la nulidad de sus resoluciones, la remisión del expe- 
diente administrativo que dio origen al acto que se impugna judicialmente constituye un requisito especial de admisibilidad de la demanda. Es decir, sin el expediente administrativo no se admitirá la demanda.

Si lo que se pretende es impugnar la aplicación de una sanción administrativa, en virtud del principio de presunción de inocencia, la carga de probar los hechos que configuran la infracción corresponde a la entidad administrativa demandada.

\subsection{Medios impugnatorios}

Los medios impugnatorios previstos en el artículo 35 del TUO de la LPCA (reposición, apelación, casación y queja) son los mismos que regula nuestro Código Procesal Civil.

Donde se aprecian diferencias es en lo relativo al recurso de casación, pues en el proceso contencioso-administrativo se establece cuantía para admitir dicho recurso, señalándose que procede en los casos que versen sobre pretensiones no cuantificables; y tratándose de pretensiones cuantificables, procederá cuando la cuantía del acto impugnado sea superior a 140 unidades de referencia procesal (U.R.P.) o cuando dicho acto provenga de autoridad de competencia provincial, regional o nacional, $y$, por excepción, de autoridad administrativa distrital.

\section{Sobre la oralidad en el proceso contencioso-administrativo}

La teoría general del proceso contencioso-administrativo se sustenta en los postulados de la teoría general del proceso. Ambos tienen un tronco común, diferenciándose el primero, como categoría jurídica, "en función de la peculiar posición de la Administración Pública como demandada y porque a veces se requiere de una actuación administrativa previa a la postulación de una pretensión procesal administrativa" (Huapaya 2006: 482). Por ello, cuando se desarrolla la oralidad en el proceso contencioso administrativo, necesariamente se tendrá que recurrir a este tronco común que es la teoría general de proceso, de donde se recoge aquel instrumento.

Para Ramos Méndez (1997: 323), “dentro del carácter reglado de las normas de procedimiento existe una pluralidad de opciones en cuanto a la disposición u ordenación de la actividad procesal. Estas se suelen presentar como series contrapuestas, que permiten la elección de una u otra alternativa con criterios de oportunidad". Entre estas opciones que 
surgen podemos citar a "la oralidad y a la escritura", cuya distinción se basa en el predominio de la forma oral o de la forma escrita en el desarrollo de las actuaciones procesales. Cabe indicar que la elección entre una $\mathrm{u}$ otra obedece a las necesidades del proceso, a los medios y a la adecuación de los recursos.

En cuanto a la oralidad del proceso, no existe uniformidad en su tratamiento. Determinados autores la definen como un principio, señalando que "sirve de sustento a la nueva tendencia de considerar el proceso como un asunto público, donde la figura del juez cobra especial preponderancia, asumiendo poderes de dirección" (Morales Godo 2005: 59-60). Otros, siguiendo una corriente más moderna, la definen como un instrumento.

Coincidimos con quienes la definen como un instrumento, puesto que los principios son los enunciados normativos más generales que, sin perjuicio de no haber sido integrados al ordenamiento jurídico, forman parte de él porque sirven de fundamento a otros enunciados normativos particulares o recogen de manera abstracta el contenido de un grupo de ellos. Estos principios son utilizados por la judicatura, los legisladores, los creadores de doctrina, sea para integrar lagunas o vacíos normativos, sea para interpretar normas jurídicas cuya aplicación resulta dudosa. En cambio, instrumento es cualquier objeto que se usa como medio para arribar a un fin. La oralidad es, por lo tanto, un medio o recurso para arribar a lo que se desea conseguir; en este caso, es el medio por el cual se permite que se cumplan los principios y garantías del debido proceso.

Diversos autores (Calamandrei 1965: 450; Chiovenda 1925: 6) manifiestan que la expresión oralidad, en su correcta acepción jurídico-procesal, recoge sintéticamente un conjunto de principios:

a) Inmediación. Situación que envuelve al juez y las personas cuyas declaraciones aquel debe recoger y valorar. Las diversas actuaciones se deben verificar ante un mismo juez o tribunal, que decide la controversia habiendo asistido a la producción de la prueba y habiendo tenido relación directa con las partes.

b) Concentración. La causa debe sustanciarse en el menor número de actos procesales, al realizarse en una audiencia o en el menor número posible de audiencias sucesivas, a fin de que el dictado de la sentencia se sustente en la prueba y en el debate oral. 
c) Celeridad y economía. En el proceso escrito, las declaraciones entre las partes procesales están separadas por intervalos que permiten las respuestas correspondientes; se fracciona en una serie de fases o de episodios, con la posibilidad de impugnar separadamente las resoluciones interlocutorias. Por el contrario, en el proceso oral, al estar presentes las partes, la respuesta sigue a la pregunta. El debate oral es contextual y no admite interrupciones o reenvíos, a diferencia del proceso escrito, que es disperso y desconcentrado.

d) Publicidad. En un proceso que permite el control de la actividad jurisdiccional y forense por las partes y la opinión pública, se refuerza la confianza del pueblo en la justicia, al poder conocer lo actuado dentro del proceso.

El concepto de oralidad también ha ido variando: para algunos, se sostiene en la necesidad de que la resolución judicial se base solo en material procesal actuado oralmente. En el sentido moderno del término, no se limita a la simple discusión oral, sino que implica poner al juez en contacto directo con las partes, los testigos, los peritos, las pruebas en general, lo que le facilita decidir. Es una gran ventaja para el juez en su afán de llegar a la verdad real y no solo a la verdad formal. La oralidad implica celeridad, y si bien esta podría no ser conveniente para dilucidar cierto tipo de problemas judiciales con alto grado de complejidad, estos no constituyen la regla, sino la excepción.

El sustento constitucional de la oralidad en el proceso contenciosoadministrativo se encuentra en el inciso 4) del artículo 139 de la Constitución, ${ }^{11}$ el que hace referencia a que los procesos son públicos. La oralidad también encuentra sustento en diversos tratados internacionales ratificados por el Estado peruano:

1. En el artículo 10 de la Declaración Universal de los Derechos Humanos, que señala: "Toda persona tiene derecho, en condiciones de plena igualdad, a ser oída públicamente".

11 Constitución Política del Perú

Articulo 139.- Principios de la administración de justicia.

Son principios y derechos de la función jurisdiccional:

$[\ldots]$

4. La publicidad en los procesos, salvo disposición contraria de la ley. Los procesos judiciales por responsabilidad cometidos por medio de la prensa y los que se refieren a derechos fundamentales garantizados por la Constitución, son siempre públicos. [...]. 
2. En el artículo 8 de la Convención Americana sobre Derechos Humanos - Pacto de San José-, referido a las garantías judiciales.

3. En el artículo 14 del Pacto Internacional de los Derechos Civiles y Políticos, que dispone: “Toda persona tendrá derecho a ser oída públicamente y con las debidas garantías por un tribunal competente, independiente e imparcial, establecido por la ley, en la substanciación de cualquier acusación de carácter penal formulada contra ella o para la determinación de sus derechos u obligaciones de carácter civil [...]; pero toda sentencia en materia contenciosa será pública".

Precisamente, uno de los autores que ha desarrollado el tema de la oralidad, Ernesto Jinesta, indica que la oralidad ofrece una mayor utilidad del proceso al cumplir con el principio formulado por las convenciones internacionales como el derecho al "debido proceso" o "garantía de audiencia"; la oralidad, en este sentido, vendría a ser la expresión más genuina de las garantías de audiencia: por medio de ella, los tribunales de justicia llegan a conocer mejor los asuntos. El juez no tiene que esperar a dictar la sentencia, como en los procesos en que rige el principio de la escrituralidad, para conocer de la materia que las partes llevan a su conocimiento. Técnicamente, se ha dicho que en este tipo de procesos es necesaria la presencia del juez desde el momento en que se interpone, mientras prosiga en su función y hasta su fin. Con la oralidad se consigue el conocimiento del asunto; ello interesa al Estado para poder fallar con mayor justicia. Solo si los órganos jurisdiccionales han tenido plena cognición podrá reputarse que se hallan en condiciones de despachar el asunto con perfecto conocimiento de causa y ajustándose a la realidad $y$, por ende, a la justicia.

La oralidad contribuye a la democratización de la justicia y del derecho, puesto que se requiere un juez que, además de un rol activo director e impulsor del proceso-, esto es, que dirija, ordene y agilice el proceso, asuma un papel asistencial interactuando con las partes para determinar y delimitar el objeto del proceso, los hechos controvertidos y la prueba admisible y pertinente, esto es, colaborando en la búsqueda de la verdad real y asegurando una igualdad real entre las partes, de tal manera que la parte victoriosa sea la que probablemente tiene la razón y no la que posee más medios económicos para pagar a un representante hábil que complique el proceso en aras de 
los intereses de su representante y resista la lentitud del proceso (Jinesta 1999: 155-156).

La oralidad permite una función moralizante, porque da transparencia al proceso al contribuir, por su inmediatez, a evitar las estrategias de los litigantes que afecten la buena fe y la lealtad procesal a que se encuentran obligados los intervinientes en el proceso.

Entre los aspectos negativos de la oralidad está el que las partes se exponen a sorpresas, omisiones y errores, dada la flexibilidad inherente a un proceso oral, lo que atenta contra la seguridad y la certeza. También se cuestiona que podría comprometerse la imparcialidad o neutralidad del juez, por su rol activo y asistencial en la oralidad, pero esta no significa parcialidad, pues aquel debe servir ante todo a la justicia, la igualdad y la verdad. El buen juez sabe distinguir antes de asumir un papel de mero espectador insensible a la realidad o de director activo.

El proceso oral requiere más magistrados. Que el magistrado lleve en forma personal las audiencias implica aprender a estructurar mejor su tiempo en cada causa y que el personal este capacitado adecuadamente. Esto implica invertir en la justicia - para que se establezcan estándares de carga procesal razonable-, en cantidad de magistrados y en el personal necesario para manejar la carga.

En aquellos procesos de consustancial y extrema complejidad de los aspectos de fondo debatidos - dada la trascendencia económica, financiera y social de los asuntos que se ventilan en la jurisdicción contencioso-administrativa y la existencia de una producción legislativa y reglamentaria asistemática, caótica, profusa y progresiva - no sería pertinente un proceso oral para resolver el conflicto.

\section{Conclusiones}

1. Como se puede advertir, la oralidad en el proceso contenciosoadministrativo ha ido de más a menos: en un primer momento, cuando se tramitaba como proceso abreviado, se realizaban dos audiencias, cumpliéndose con los requisitos de inmediación; luego la oralidad se ha ido eliminando, para regresar a un proceso principalmente escrito.

2. No se da la misma problemática en todos los procesos contencioso-administrativos. Existen procesos en que los hechos son incontrovertidos y no se tiene que resolver más que cuestiones de 
derecho; en otros, habiendo hechos controvertidos, se debe resolver con fundamento en una prueba documental - en esta clase están el proceso urgente y el proceso contencioso-administrativo en la mayoría de los casos, salvo cuando también se pretenda una indemnización -; y en otros, finalmente, habiendo hechos controvertidos, se requieren elementos de convicción basados no solo en pruebas documentales, sino en declaraciones de parte, de testigos, pericias e inspecciones judiciales. En cada uno de estos supuestos, el requisito de oralidad tendrá un peso distinto: menor en los dos primeros casos y mayor en el último.

3. Se requiere de una judicatura especializada, previamente capacitada - de manera adecuada y suficiente- para comprender y asimilar la trascendencia de los principios de celeridad, concentración, inmediación, publicidad, igualdad y suplencia de oficio. El juez debe aprender a adoptar un rol activo y asistencial de las partes en el proceso; mediante el ejercicio efectivo de los poderes que se le otorgan, debe procurar la igualdad real de las partes y la defensa de la tutela judicial efectiva consagrada por el numeral 3) del artículo 139 de la Constitución, que constituye un parámetro para determinar la naturaleza del proceso contencioso-administrativo.

4. En el Perú, como el proceso contencioso-administrativo tiene por objeto no solo la declaración judicial de invalidez de las actuaciones, contrarias al ordenamiento jurídico, de la Administración Pública, sino también el restablecimiento, para el particular, de las situaciones ilegítimamente perturbadas por esta, con una impartición de justicia lenta se deslegitima el sistema. Pero dar una justicia efectiva implica invertir, otorgar los recursos presupuestarios adecuados, correspondiendo a los otros poderes verificar si se cumple con las metas de gestión.

5. Solo mediante la concentración y la inmediatez - aspectos inherentes a la oralidad - se pueden aumentar los poderes del juez para buscar la verdad, lograr la simplicidad y lealtad del contradictorio, resolver dentro de los plazos cuando el juzgador ha intervenido en las audiencias, reducir los formalismos y acelerar los procesos. Pero para ello se requerirá de una cantidad adecuada de jueces, el conocimiento de los procesos y los medios logísticos necesarios para la tramitación de estos. 


\section{Bibliografía}

Calamandrei, Piero (1965). Oralidad en el proceso. Obra de derecho. Volumen I. Nápoles: Morano.

Chiovenda, Giuseppe (1925). Principio de derecho procesal civil. Volumen II. Madrid: Reus.

Danós Ordóñez, Jorge (s/f). "El proceso contencioso administrativo en el Perú". <http://www.jusdem.org.pe/webhechos/N010/contencioso\%20administrativo.htm>.

Huapaya Tapia, Ramón (2006). Tratado del proceso contencioso administrativo. Lima: Jurista.

Jinesta, Ernesto (1999). "La oralidad en el proceso contencioso administrativo". Ivstutuia. Año 13, núms. 155-156, noviembre-diciembre. Costa Rica.

Morales Godo, Juan (2005). Instituciones de derecho procesal. Lima: Palestra.

Priori Posada, Giovanni (2006). Comentarios a la Ley del Proceso Contencioso-Administrativo. 3. ${ }^{\text {a }}$ edición. Lima: Ara.

Ramos Méndez, Francisco (1997). El sistema procesal español. Barcelona: Bosch. 